\title{
Microwave-assisted chemical reduction routes for direct synthesis of Fe-Pt nanoparticles in ordered face centered tetragonal $\mathrm{L1}_{\mathbf{0}}$ phase
}

\author{
S. Acharya $\cdot$ K. Singh
}

Received: 19 April 2011 / Accepted: 28 April 2011/Published online: 13 May 2011

(C) The Author(s) 2011. This article is published with open access at Springerlink.com

\begin{abstract}
In the present work, microwave-assisted chemical reduction route has been explored for the direct synthesis of face centered tetragonal (fct) $\mathrm{L}_{0}$ phase of Fe-Pt nanoparticles. Effects of microwave power and irradiation time on the growth process were investigated. Using this facile and high yield technique we could tune particle size from 7 to $17 \mathrm{~nm}$. The as-prepared Fe-Pt NPs were observed in ordered fct $\mathrm{L} 1_{0}$ phase without any postsynthesis treatment. The particle size and magnetic properties of the as-prepared $\mathrm{Fe}-\mathrm{Pt}$ were found to be very sensitive to the microwave irradiation power, while influence of exposure time was insignificant. The hysteresis measurements were performed at room temperature $(300 \mathrm{~K})$ to study magnetic properties of as-synthesized $\mathrm{Fe}-\mathrm{Pt}$ as a function of crystallite size. All specimens of $\mathrm{Fe}-\mathrm{Pt}$ were found to exhibit ferromagnetic behavior at room temperature. Coercivity and saturation magnetization were observed to be decreasing with diminishing particle size. The microwave-assisted route is found to be a simple technique for direct synthesis of metal alloys and may prove to be a potential tool of high density data storage materials such as $\mathrm{Fe}-\mathrm{Pt}$.
\end{abstract}

Keywords Fe-Pt nanoparticles .

Direct synthesis $\mathrm{L} 1_{0}$ phase · Microwave-assisted synthesis · Chemical reduction

S. Acharya $(\bowtie) \cdot$ K. Singh

Department of Physics, Rashtrasant Tukdoji Maharaj Nagpur

University, Nagpur 440033, Maharashtra, India

e-mail:saha275@yahoo.com

\section{Introduction}

The chemically ordered nanoparticles (NPs) of Fe-Pt alloy in $\mathrm{L} 1_{0}$ phase have been recognized as promising materials for a new generation of ultrahigh density magnetic recording media (Weller and Moser 1999; Christodoulides et al. 2000; Peng et al. 2003). Large magnetocrystalline anisotropy $\left(\mathrm{Ku}=7 \times 10^{6} \mathrm{~J} / \mathrm{cm}^{3}\right)$ and excellent hard magnetic properties of $\mathrm{Fe}-\mathrm{Pt} \mathrm{NPs}$ in $\mathrm{L} 1_{0}$ phase have been demonstrated (Sun et al. 2000; Zeng et al. 2002a, b). Unfortunately, as-synthesized Fe-PT NPs assume a disordered face-centered cubic (fcc) structure that has low magnetocrystalline anisotropy. Heat treatment is necessary to convert the fcc structure to the ordered face centered tetragonal (fct) structure $\left(\mathrm{L} 1_{0}\right.$ phase). The high temperature treatments have been observed to lead to the coalescence and agglomeration of NPs resulting in suppressing the recording density evolution (Zeng et al. 2002a, b; Kodama et al. 2005). The direct synthesis of Fe-Pt NPs in ordered fct structure $\left(\mathrm{L} 1_{0}\right.$ phase) is highly desirable to avoid high temperature treatment. The literature on $\mathrm{Fe}-\mathrm{Pt}$ reveals that there are very few references on directly synthesized, chemically ordered fct Fe-Pt NPs. Jeyadevan et al. 2003 have investigated the direct synthesis route for chemically ordered fct Fe-Pt NPs by co-reduction of iron and platinum ions in polyol. The controlled synthesis conditions such as reaction temperature and type of polyol are found to be the effective parameters in predicting structure of as-synthesized Fe-Pt NPs. Microwave-assisted polyol method to directly synthesize Fe-Pt NPs has been reported (Minamia et al. 2005). However, the Fe-Pt NPs that have been synthesized by this method were observed to be highly coalescence and agglomerated. The chemical synthesis route for preparation of monodispersed $\mathrm{Fe}-\mathrm{Pt}$ using $\mathrm{Fe}(\mathrm{CO})_{5}$ and $\mathrm{Pt}(\mathrm{acac})_{2}$ in the presence of oleic acid and oleyl amine as 
surfactants have been explored (Colak and Hadjipanayis 2009). The process parameters including the injection temperature of the precursors, the injection time of the surfactants, the reaction solvent, the refluxing temperature and heating rate to the refluxing temperature have been found to play an essential role in controlling the size and shape of the particles. The as-made Fe-Pt NPs are in the chemically disordered fcc structure and high temperature annealing is needed for ordered fct structure, which increases the particle size.

Although, the effect of particle size on the ferromagnetism of the low dimensional magnet is very well recognized, there are not many reports on the dependence of the particle size on the magnetic properties such as Curie temperature, coercivity and magnetization of $\mathrm{L}_{0}-\mathrm{Fe}-\mathrm{Pt}$ phase (Rong et al. 2006; Nandana et al. 2007; Chen et al. 2004). In the present work, we report our efforts of direct synthesis of NPs of Fe-Pt ordered fct structure ( $\mathrm{L} 1_{0}$ phase) using microwave-assisted chemical reduction routes. Effects of microwave power and irradiation time on the particle size and magnetic properties are studied.

\section{Experimental methods}

$\mathrm{Fe}-\mathrm{Pt}$ NPs were prepared via chemical reduction of $\mathrm{Pt}(\mathrm{acac})_{2}$ and thermal decomposition of $\mathrm{Fe}(\mathrm{CO})_{5}$ in the presence of oleic acid and oleyl amine as surfactants. Earlier, this method has been used to synthesize NPs of $\mathrm{Fe}-\mathrm{Pt}$ in different sizes and shapes using conventional way of heating and changing proportion of oleic acid and oleyl amine (Sun et al. 2000; Colak and Hadjipanayis 2009; Chen et al. 2004). In the present work, we have used microwave as heating source. To the best of our knowledge, this is the first report on direct synthesis of $\mathrm{L} 1_{0}$ phase of Fe-Pt NPs by this method. The syntheses were carried out using standard airless techniques in argon atmosphere. In a typical procedure, $1 \mathrm{mmol}$ of $\mathrm{Pt}(\mathrm{acac})_{2}$ was added to $25 \mathrm{ml}$ benzyl ether. After purging with argon for $30 \mathrm{~min}$ at room temperature the flask was heated up to $100^{\circ} \mathrm{C}$ for $15 \mathrm{~min}$ and a designated amount of oleic acid and oleyl amine was added. $\mathrm{Fe}(\mathrm{CO})_{5}(2 \mathrm{mmol})$ was added when the platinum precursor dissolved completely. The dissolution of $\mathrm{Pt}(\mathrm{acac})_{2}$ in solvent could be followed experimentally by the change in color of the solution from yellow to transparent yellow. After the addition of $\mathrm{Fe}(\mathrm{CO})_{5}$, the mixture was made to react in a $250 \mathrm{~cm}^{3}$ round-bottomed flask with condenser attachment kept in a microwave refluxing system. This was a microwave chamber of $360 \mathrm{~mm} \times$ $210 \mathrm{~mm} \times 430 \mathrm{~mm}$ dimensions with a $2.45 \mathrm{GHz}$ frequency multimode source. Maximum deliverable power output was $700 \mathrm{~W}$. We prepared the samples for different microwave synthesis conditions by varying the scale of microwave power level from 120 to $420 \mathrm{~W}$ and irradiation time 15-65 min under the argon blanket. The reaction products were cooled down at room temperature and $80 \mathrm{ml}$ of anhydrous ethanol was then added to precipitate the particles. The precipitates were centrifuged four times, and then dispersed in toluene. For the X-ray diffraction and magnetic characterization, the nanoparticles were dropcasted from the original solution (without dilution) on the Si-substrate. For the transmission electron microscopy (TEM), the solutions of nanoparticles were diluted and used to deposit the particles on carbon-coated TEM grids for subsequent imaging and analysis.

\section{Results and discussion}

Structural characterization of as-synthesized $\mathrm{Fe}-\mathrm{Pt}$

The measurements of X-ray diffraction (XRD) of as-synthesized $\mathrm{Fe}-\mathrm{Pt}$ NPs were carried out in the reflection geometry using an X-ray diffractometer D8 Advanced Bruker instrument with $\mathrm{Cu} \mathrm{K} \alpha$ radiation (1.54 $\AA$ ) at a scanning rate of $1^{\circ} \min ^{-1}$. The transmission electron microscopy (TEM) was studied using a Technai $20 \mathrm{G}^{2}$. Energy-dispersive X-ray spectroscopy measurements were obtained using a scanning electron microscopy JEOL JSM6360A. The magnetic properties of the Fe-Pt nanoparticles sample were determined using a quantum design DC superconducting Quantum Interference Device magnetometer (SQUID).

XRD patterns of as-synthesized Fe-Pt NPs at different microwave power and exposure times are shown in Figs. 1 and 2, respectively. Diffraction at (001) and (110) planes represent superlattice peaks of $\mathrm{L}_{0}$ structure. Thus, the direct formation of $\mathrm{L}_{0}$ phase in as-synthesized Fe-Pt NPs can be confirmed from both XRD spectra (Figs. 1, 2). These are evident for the chemically ordered fct structure of $\mathrm{Fe}-\mathrm{Pt}$, which are obtained directly without any postannealing treatment. All samples were synthesized in the form of stable colloidal solution for all power levels of the microwave. The width of the XRD peaks provides information about the X-ray coherence length which is close to the average size of the single crystalline domain inside the nanocrystal. Using Scherrer formula, average nanocrystallite sizes were calculated for all samples from the width of (111) peak of XRD and listed in Table 1. Systematic analysis of the XRD data reveals that the variations of microwave power during synthesis strongly influence the size of crystallites. With the increase of microwave power from 120 to $420 \mathrm{~W}$, average size of crystallites is found to be increased in the range of 7-17 $\mathrm{nm}$. On the other hand, variation of microwave exposure time from 15 to $65 \mathrm{~min}$ at constant power $360 \mathrm{~W}$, the size of crystallites is obtained to 
be around $15 \mathrm{~nm}$ for all samples. It can also be viewed from XRD (Fig. 2). Subsequent increase of microwave power results in detectable changes in particle size. These are consistent with the TEM images (Figs. 3, 4). TEM images for samples synthesized at different power and constant time (25 min) are shown in Fig. 3. The increase in size of crystallite with microwave power can be observed from Fig. 3a-d. TEM images of samples synthesized at a constant power of $360 \mathrm{~W}$ for different exposure time are presented in Fig. $4 \mathrm{a}-\mathrm{c}$. It can be concluded that particle size is independent upon microwave exposure time.

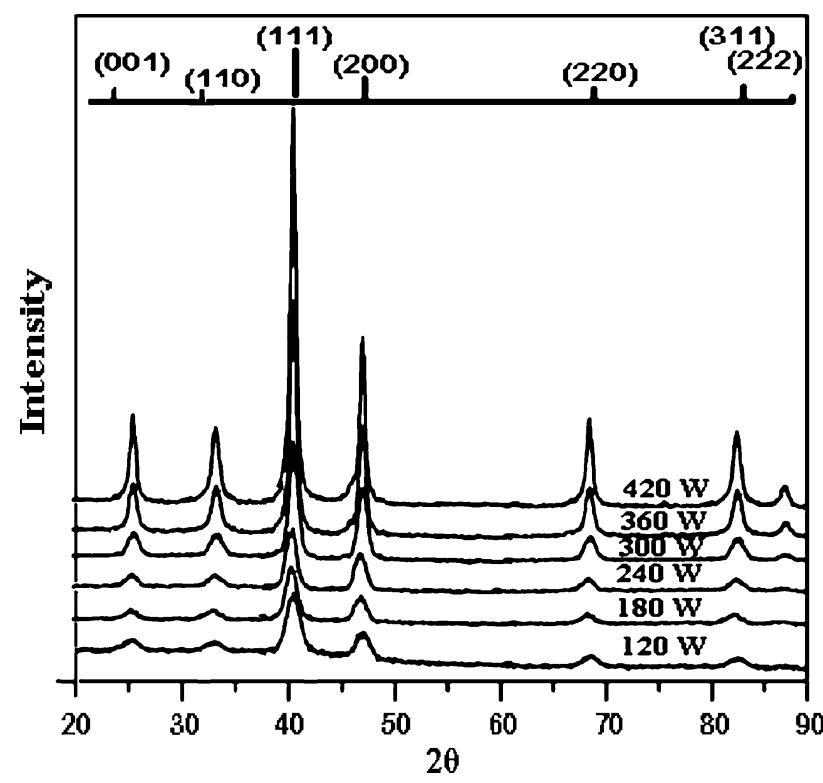

Fig. $1 X R D$ patters of as-synthesized Fe-Pt nanoparticles prepared at different power level of microwave

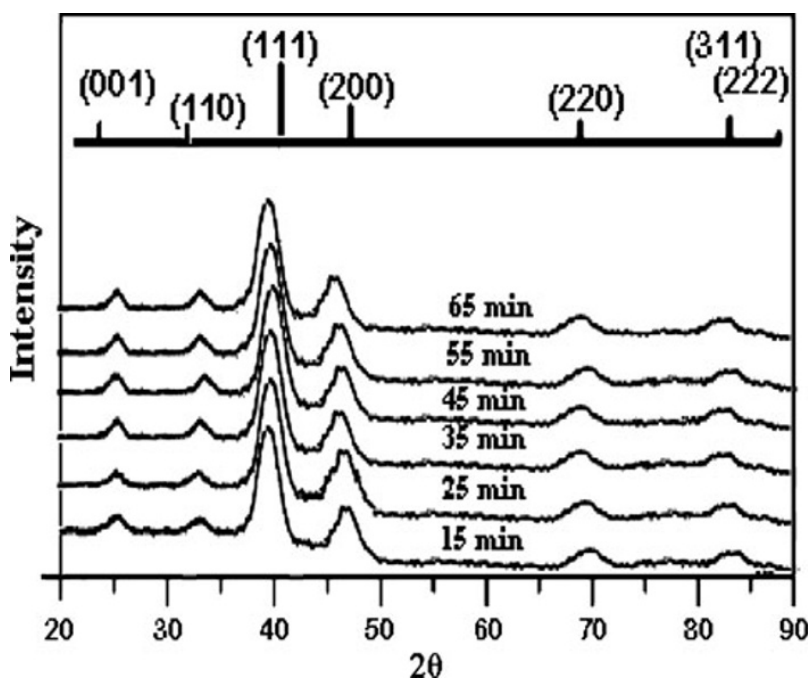

Fig. 2 XRD patters of as-synthesized Fe-Pt nanoparticles prepared at different exposure time of microwave
Average crystallite size of Fe-Pt NPs, calculated by XRD and observed from TEM for all microwave synthesis conditions are listed in Table 1. Compositions of Fe:Pt NPs were determined by EDX technique. The EDX measurements indicate that all compositions are very close to the ratio 55:45 for Fe:Pt.

Growth process of $\mathrm{Fe}-\mathrm{Pt}$ nanoparticles by microwave-assisted chemical route

Generally, in nanomaterials synthesis by chemical route, the particle size can be tuned by the rate of nucleation. Fast nucleation during the reaction leads to the formation of high concentration of seeds. Consequently, low concentrations of monomer are available in the reactant for the growth of seeds yielding small crystallites. However, slow nucleation provides low concentration of seeds, consuming the same amount of monomer and fastening the growth of crystallites. Hence, control over nucleation rate during the reaction is a very important criterion to control the size of crystallites on nanoscale by avoiding Ostwald ripening. Conditions of synthesis play a very important role in the manipulation of the rate of nucleation. In the present work, microwave power was found to regulate the size of crystallite of Fe-Pt. It implies that the rate of nucleation is controlled by the power levels of microwave. The role of power levels on the rate of nucleation should be understood.

During microwave processing of chemical reaction, temperature of reaction depends upon the power dissipated in the solvent. The dissipation of power per unit volume $(P)$ is described by $P=\sigma(E)^{2}$, where $\sigma$ is the conductivity and $E$ is the electric field related to applied microwave power. It means that the reaction temperature is manipulated by the power level of microwave.

In chemical synthesis route, rate of heating and the temperature of the reaction play dominant role in controlling the growth of nucleation. In microwave-assisted synthesis, in contrast to convective heating, dielectric heating raises the temperature of the total volume of the reactants by transforming energy selectively to microwave absorbing materials. The larger the microwave cross-section for a particular constituent, the more dramatic the heating process is. The intrinsic temperature localized around the ion is significantly higher than that of the bulk solution. It can therefore be understood that localized heating drives the rate of nucleation and controls the Ostwald ripening process. The microwave power level decides the localized heating rate. On the other hand, exposure of reactant in microwave at constant power as function of time has no significant change in intrinsic temperature. This behavior is attributed to constant rate of nucleation and it may avoid Ostwald ripening processes. 
Table 1 Particle size from XRD and TEM of as-synthesized Fe-Pt nanoparticles at different microwave conditions of synthesis

\begin{tabular}{|c|c|c|c|c|c|}
\hline \multicolumn{3}{|c|}{ Microwave exposure time $25 \mathrm{~min}$} & \multicolumn{3}{|l|}{ Microwave power $360 \mathrm{~W}$} \\
\hline \multirow[t]{2}{*}{ Microwave power $(\mathrm{W})$} & \multicolumn{2}{|c|}{$\mathrm{Fe}-\mathrm{Pt}$ particle size $(\mathrm{nm})$ from } & \multirow[t]{2}{*}{ Microwave exposure time (min) } & \multicolumn{2}{|c|}{$\mathrm{Fe}-\mathrm{Pt}$ particle size $(\mathrm{nm})$ from } \\
\hline & XRD & TEM & & XRD & TEM \\
\hline 120 & 7 & & 15 & 14.5 & \\
\hline 180 & 8 & & 25 & 15 & \\
\hline 240 & 10 & 7 & 35 & 15 & 15 \\
\hline 300 & 13 & 10 & 45 & 15 & 15 \\
\hline 360 & 15 & 15 & 55 & 15.7 & 15 \\
\hline 420 & 17 & 20 & 65 & 16 & 15 \\
\hline
\end{tabular}
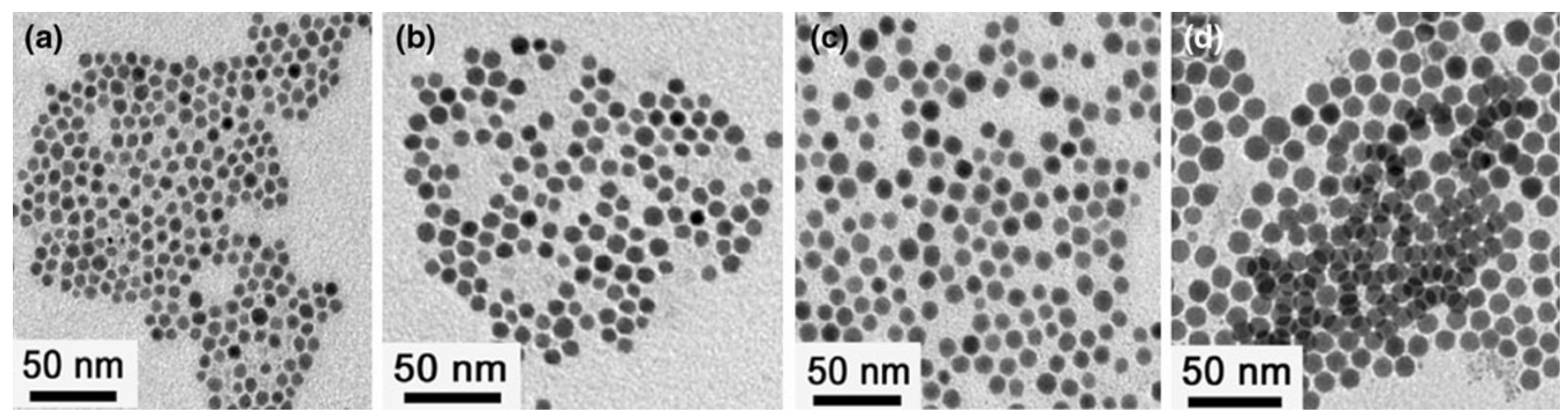

Fig. 3 TEM images of as-synthesized Fe-Pt at different microwave power, a $240 \mathrm{~W}$, b $300 \mathrm{~W}$, c $360 \mathrm{~W}$, and d $420 \mathrm{~W}$ for 25 min exposure time

Fig. 4 TEM images of assynthesized Fe-Pt at different microwave exposure time a $25 \mathrm{~min}$, b $45 \mathrm{~min}$ and c $65 \mathrm{~min}$ for power $360 \mathrm{~W}$
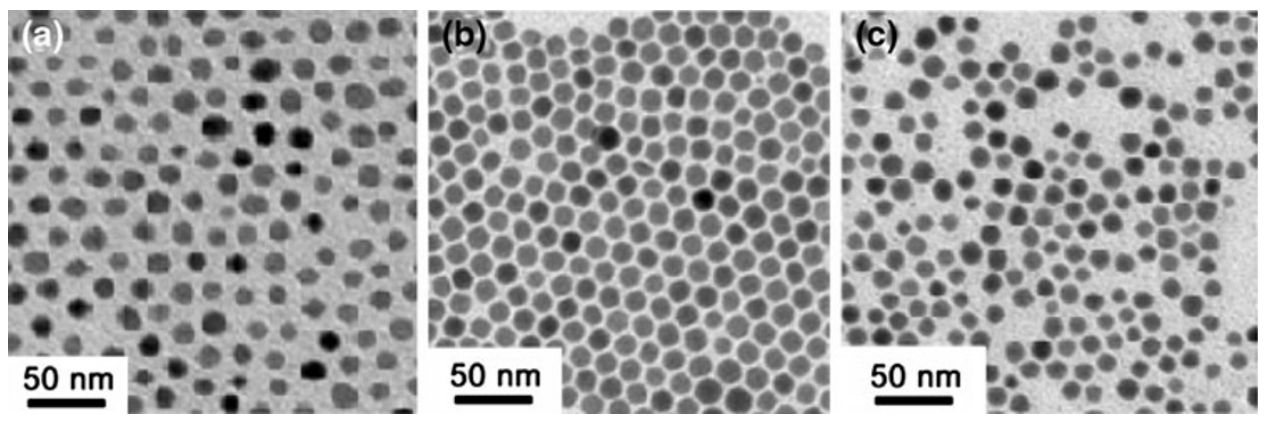

The as-synthesized Fe-Pt NPs are confirmed to be in chemically ordered fct structure from XRD analysis. Figure 5 shows a set of measurements performed for characterizing the size-dependent magnetic properties of assynthesized Fe-Pt NPs. The hysteresis measurements were carried out at room temperature $(300 \mathrm{~K})$ on nanocrystals of different sizes. From the hysteresis loops, it can be concluded that all the Fe-Pt samples are found to exhibit ferromagnetic behavior at room temperature (Fig. 5). These results reveal that coercivity decreases with decreasing particle size. This may be due to easy reorientation of the magnetic moment for small particles. The drop in the saturation magnetization with decreasing nanoparticle size can be attributed to an increase of the surface-tovolume ratio.

\section{Conclusion}

The Fe-Pt nanoparticles were synthesized by microwaveassisted chemical reduction route. The as-synthesized nanoparticles were found to be ordered fct $\mathrm{L} 1_{0}$ phase. We have succeeded in the direct synthesis of $\mathrm{L}_{0}$ structure of $\mathrm{Fe}-\mathrm{Pt}$ without any post-synthesis treatments by microwave-assisted route. The synthesis route also allows the easy control of the size of particles by simply changing microwave power level. The size of the particles was tuned in the range of $7-17 \mathrm{~nm}$ by varying power level by 120-420 W. Magnetic investigations at room temperature reveal ferromagnetic behavior for all $\mathrm{Fe}-\mathrm{Pt}$ samples having different particle size. The coercivity and saturation magnetization were observed to decrease with decreasing 


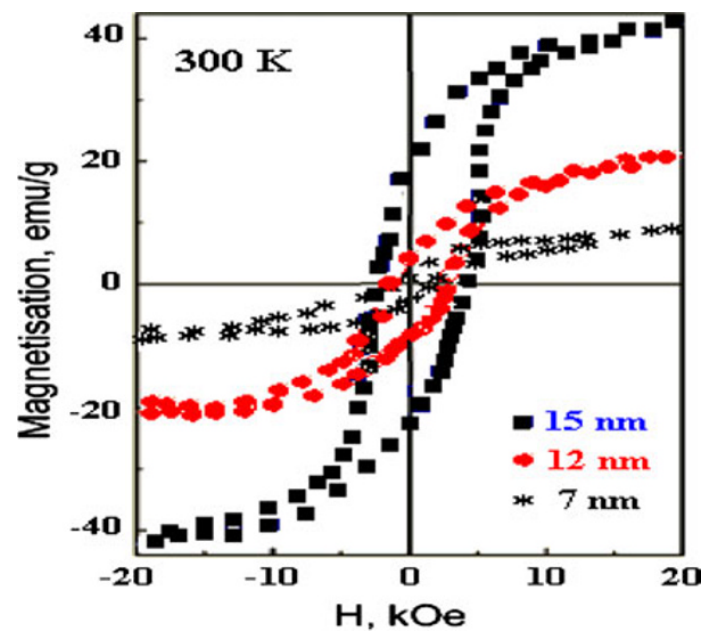

Fig. 5 Hysterisis loop of Fe-Pt at room temperature (300 K)

particle size. For 15, 12, $7 \mathrm{~nm}$ particles coercivity was found to be 5,4 and $3.5 \mathrm{KOe}$, respectively. Saturation magnetization was observed to be 42, 20 and $11 \mathrm{emu} / \mathrm{g}$ for the $15,12,7 \mathrm{~nm}$ particles of $\mathrm{Fe}-\mathrm{Pt}$, respectively.

Acknowledgments This work is supported by DST through FIST Program. The authors also thank Dr S.K. Kulkarni, Professor, IISER, Pune for magnetic characterization and Dr R.M. Singru, Professor, IIT Kanpur for fruitful discussion and suggestion.

Open Access This article is distributed under the terms of the Creative Commons Attribution License which permits any use, distribution, and reproduction in any medium, provided the original author(s) and source are credited.

\section{References}

Chen M, Liu JP, Sun S (2004) One step synthesis of FePt nanoparticles with tunable size. J Am Chem Soc 126:8394-8395
Christodoulides JA, Huang Y, Zhang Y, Hadjipanayis GC, Panagiotopoulos I, Niarchs D (2000) CoPt and FePt thin film for high density recording media. J Appl Phys 87:6938-6970

Colak L, Hadjipanayis GC (2009) Chemically synthesized FePt nanoparticles with controlled particle size, shape and composition. Nanotechnol 20:485602-485609

Jeyadevan B, Hobo A, Urakawa K, Chinnasamy CN, Shinoda K, Tohji K (2003) Towards direct synthesis of fct-FePt nanoparticles by chemical route. J Appl Phys 93:7574-7576

Kodama H, Monose S, Sugimoto T, Uzumaki T, Tanaka A (2005) Chemically synthesized FePt nanoparticles material for ultrahigh density recording. IEEE Trans Magn 41:665-669

Minamia R, Kitamoto Y, Chikata T, Kato S (2005) Direct synthesis of $\mathrm{L1}_{0}$ type $\mathrm{Fe}-\mathrm{Pt}$ nanoparticles using microwave-polyol method. Electrochim Acta 51:864-866

Nandana V, Elkins KE, Poudyal N, Chanbey GS, Yano K, Liu JP (2007) Size and shape control of monodisperse FePt nanoparticles. J Phys Chem C 111:4185-4189

Peng DL, Hihara T, Sumiyama K (2003) Formation and magnetic properties of $\mathrm{Fe}-\mathrm{Pt}$ alloys clusters by plasma-gas condensation. Appl Phys Lett 82:350-352

Rong C, Li D, Liu JP, Nandwana V, Poudyal N, Ding Y, Wang ZL, Zeng H (2006) Size dependent chemical and magnetic ordering in $\mathrm{L1}_{0}$-FePt nanoparticles. Adv Materials 18:2984-2988

Sun S, Murray CB, Weller D, Folks L, Moser A (2000) Monodisperse FePt nanoparticles and ferromagnetic FePt nanocrystal superlattices. Science 287:1989-1992

Weller S, Moser A (1999) Thermal effect limits in ultrahigh density magnetic recording. IEEE Trans Magn 35:4423-4439

Zeng H, Li J, Wang ZL, Liu JP, Sun S (2002a) Interparticle Interactions in annealed $\mathrm{FePt}$ nanoparticle assemblies. IEEE Trans Magn 38:2598-2600

Zeng H, Li J, Liu JP, Wang ZL, Sun SH (2002b) Exchange-coupled nanocomposite magnets by nanoparticles self-assembly. Nature 420:395-398 